Journal of Systems Science and Information

Dec., 2021, Vol. 9, No. 6, pp. 660-680

DOI: $10.21078 /$ JSSI-2021-660-21

\title{
Efficiency Analysis of Industrial Water Treatment in China Based on Two-stage Undesirable Fixed-sum Output DEA Model
}

\author{
Hewen MA \\ Faculty of Mathematics and Statistics, Hubei University, Wuhan 430062, China \\ E-mail: hewen.ma@stu.hubu.edu.cn \\ Baoxia GENG \\ Faculty of Mathematics and Statistics, Hubei University, Wuhan 430062, China \\ E-mail: gbx2021@stu.hubu.edu.cn \\ Yingxiong FU \\ Faculty of Mathematics and Statistics, Hubei University, Wuhan 430062, China \\ E-mail: fyx@hubu.edu.cn \\ Yi SUN* \\ School of Finance, Anhui University of Finance \& Economics, Bengbu 233030, China \\ E-mail: sunyi@aufe.edu.cn

\section{Zhao SUN} \\ Faculty of Information Technology, Macau University of Science and Technology, Macau 999078, \\ China \\ E-mail: sun.zhao.must@gmail.com
}

\begin{abstract}
China is a country with the most water consumption, so it is lack of water resources. Industry has brought serious water pollution while driving economic development, which leads to the destruction of ecological environment. With the improvement of environmental awareness, many scholars have shifted their research direction to how to improve the ecological environment. Most studies consider the whole system as a "black box", regardless of its internal structure. Therefore, a method to identify inefficiency is necessary and some suggestions for optimization are given. In this paper, a two-stage undesirable fixed-sum output data envelopment analysis (DEA) model is proposed. The industrial chemical oxygen demand (COD) emission during 2011-2015 are adjusted, and the efficiency values are calculated by heuristic search algorithm. The efficiency of 30 provinces and cities is divided into eastern, central and western regions. The model can identify the inefficient stage in industrial system, and find the source of low efficiency in the system. The analysis shows that the efficiency of eastern region is the highest, while the overall efficiency is inclined to the pollutant treatment stage. Finally, the paper puts forward some suggestions for the low efficiency areas, which can save water while ensuring economic benefits, and provide new direction for water pollution reduction and improve the ecological environment.
\end{abstract}

Keywords industrial wastewater COD emission; two-stage; undesirable fixed-sum outputs

Received August 25, 2021, accepted October 19, 2021

Supported by Doctoral Research Startup Fund of Anhui University of Finance \& Economics (85051)

*Corresponding author 


\section{Introduction}

Since the reform and opening-up, with the rapid economic development, China's industrial system has made great achievements, and has surpassed the United States to become the world's largest industrial producer ${ }^{[1]}$. As is known to all, water is vital to human life and social development. Due to the rapid growth of population and climate change, water shortage has become a worldwide problem ${ }^{[2,3]}$. Due to the large population, the per capita water resources are relatively low, the utilization and protection of water resources in China is particularly important. With the increasing attention to environmental protection, China began to take the road of green economic development ${ }^{[4]}$. The state has also formulated some environmental protection policies. For example, in the notice of "The State Council on the Issuance of the Comprehensive Work Plan for Energy Conservation and Emission Reduction During the 13th Five-Year Plan Period", the environmental and resource indicators are further strengthened: by 2020 , the energy consumption per 10,000 yuan of GDP will be reduced by $15 \%$ compared with 2015, the national COD and $\mathrm{AN}$ will be reduced by $10 \%$, and the emissions of $\mathrm{SO}_{2}$ and $\mathrm{NO}_{x}$ will be reduced by $15 \%$. To achieve this goal, we need to effectively coordinate economic development and enhance the awareness of ecological and environmental protection. In order to coordinate the relationship between economic development and ecological environment protection, it is necessary for us to find a suitable method to evaluate the efficiency between economy and environment.

\section{Literature Review}

Data envelopment analysis (DEA) is a relatively effective linear programming method for the evaluation of decision-making unit (DMU) input and output. As a non-parametric method, it doesn't need to clarify the functional relationship between variables and dimensionless, as well as it has obvious advantages in dealing with multi-input and output indicators ${ }^{[5]}$. Therefore, many scholars apply DEA method to the evaluation of various fields in China, such as regional transportation system $(\mathrm{RTS})^{[6]}$, aircraft support concept evaluation ${ }^{[7]}$, regional energy efficiency in China ${ }^{[8]}$, and also use DEA method to evaluate environmental problems. Wang, et al. ${ }^{[9]}$ proposed a two-stage model based on DEA to analyze the efficiency of industrial water system. Tian, et al. ${ }^{[10]}$ used DEA method to analyze the agricultural high-efficiency watersaving efficiency of counties in Xinjiang. Pan, et al. ${ }^{[11]}$ proposed an integrated DEA model. Deng, et al. ${ }^{[12]}$ and Chang, et al. ${ }^{[13]}$ using the slack based measure data envelopment analysis (SBM-DEA) model to estimate China's water resources utilization efficiency. Zhu, et al. ${ }^{[14]}$ analyzed and evaluated the water resource utilization efficiency based on the DEA method. Li, et al. ${ }^{[15]}$ evaluated the environmental efficiency of industrial systems with new network slackbased model (NSBM) and DEA window analysis. Hu, et al. ${ }^{[16]}$ used the ecological efficiency model focusing on undesirable output to evaluate the water utilization efficiency. Wang, et al. ${ }^{[17]}$ proposed a two-stage DEA approach with game cross efficiency. Song, et al. ${ }^{[18]}$ made a systematic study on the SBM model considering undesirable output, and further extended the SBM model from the perspective of network analysis. Chen, et al. ${ }^{[19]}$ analyzed the efficiency of representative sewage treatment plants in 31 provinces. Zhang, et al. ${ }^{[20]}$ established a super DEA model with undesirable output based on DEA to evaluate the regional water utilization 
efficiency in China.

In the actual production process, input minimization and output maximization are followed. When certain resources, such as labor and capital are invested, the desirable output will inevitably produce undesirable output, such as industrial wastewater, waste gas and solid waste. At that time, it can not be judged according to the traditional DEA model that the greater the output, the higher the efficiency. Therefore, when considering the efficiency evaluation of DMU with undesirable output, many scholars have carried out research on DMU with undesirable output. Hailu, et al. ${ }^{[21]}$ treated undesirable output as input and minimized input and undesirable output at the same time. Seiford and $\mathrm{Zhu}^{[22]}$ performed function transformation on the undesirable output. Here, the undesirable output is still regarded as the output, and the undesirable output multiplied by -1 is transformed into the desirable output form of the bigger the better to evaluate the environmental efficiency. However, the non-negative condition of output may not be met. Therefore, Ali, Seiford ${ }^{[23]}$ and Pastor ${ }^{[24]}$ proposed to multiply the undesirable output by -1 first, and then add a large enough positive number to ensure that the undesirable output after processing is positive. In addition, Färe, et al. ${ }^{[25]}$ took the inverse of the undesirable output through nonlinear function transformation, but the model will become nonlinear and is not conducive to solution.

In practice, DEA method can not only evaluate the cost ${ }^{[26-29]}$, but also analyze the efficiency of outputs ${ }^{[30,31]}$. The traditional DEA model ignores the internal structure, which makes the calculation efficiency high. Dividing the system into two stages can increase the calculation efficiency accurately ${ }^{[32-36]}$. Compared with the existing literature, this paper adopts the twostage undesirable fixed-sum output DEA model to analyze China's industrial system from 2011 to 2015. In order to respond to the national energy-saving and emission reduction policies, this paper analyzes the problems existing in China's industrial system from the two-stage of industrial water utilization and pollutant treatment. COD can reflect the degree of effluent pollution. High COD indicates serious water pollution ${ }^{[37]}$. Because of the country has a clear emission standard for COD, the paper fixed the COD emission of undesirable output so that it is fixed at the emission level of the current year. The first step generates the equilibrium efficient frontier, and the annual fixed industrial COD emissions will be in 30 regions (including provinces, municipalities and autonomous regions, hereinafter collectively referred to as provinces. Tibet, Taiwan, Hong Kong and Macao not included) are adjusted to make all regions effective. The second step uses heuristic search algorithm to obtain the overall efficiency and the efficiency of each stage based on the equilibrium effective frontier, find out the reasons for the low efficiency, and give improvement plans and suggestions.

\section{Model Review}

\subsection{Fixed-sum Output GEEFDEA Model}

The GEEFDEA method proposed by Yang et al. consists of two steps ${ }^{[38]}$. The first step constructs the equilibrium effective frontier, and the second step calculates the efficiency value for each DMU based on this frontier.

Suppose there are $n$ DMUs and that each $\operatorname{DMU}_{j}(j=1,2, \cdots, n)$ consumes $m$ inputs $x_{i j}$ $(i=1,2, \cdots, m ; j=1,2, \cdots, n)$ to produce $s$ variable-sum outputs $y_{r j}(r=1,2, \cdots, s)$, and 
$l$ fixed-sum outputs $f_{t j}(t=1,2, \cdots, l)$. Variable-sum outputs can be adjusted freely, while fixed-sum outputs need to satisfy the constraint $\sum_{j=1}^{n} f_{t j}=F_{t}(t=1,2, \cdots, l)$, where $F_{t}$ is a constant. Based on minimal reduction strategy ${ }^{[39]}$, the model is as follows:

$$
\begin{aligned}
\min & \sum_{j=1}^{n} \sum_{t=1}^{l} w_{t} \alpha_{t j} \\
\text { s.t. } & \frac{\sum_{r=1}^{s} u_{r} y_{r j}+\sum_{t=1}^{l} w_{t}\left(f_{t j}+\delta_{t j}\right)+\mu_{0}}{\sum_{i=1}^{m} v_{i} x_{i j}}=1, \quad j=1,2, \cdots, n, \\
& \sum_{j=1}^{n} \delta_{t j}=0, \\
& \alpha_{t j}=\max \left\{\delta_{t j}, 0\right\}, \quad j=1,2, \cdots, n, \\
& f_{t j}+\delta_{t j} \geq 0, \quad j=1,2, \cdots, n, \\
& u_{r}, v_{i}, w_{t} \geq 0 ; \delta_{t j}, \mu_{0} \text { are free, }
\end{aligned}
$$

where $u_{r}, w_{t}, v_{i}$ respectively represent the weight of the $r$ th variable-sum output, the $t$ th fixedsum output, and the $i$ th input, $\delta_{t j}$ represents the adjustment quantity of the th fixed-sum output of DMU, and $\delta_{t j}$ is free, indicating that the adjustment quantity can be positive, negative or zero.

\subsection{GEEFDEA Model of Undesirable Fixed-sum Output}

The GEEFDEA model of undesirable fixed-sum output is similar to model (1). The difference is that for a certain amount of input, the more desirable output is more effective, while the less undesirable output is better. Therefore, the undesirable output can be regarded as input to minimize it, and model (2) can be obtained as follows:

$$
\begin{array}{ll}
\min & \sum_{j=1}^{n} \sum_{t=1}^{l} w_{t} \alpha_{t j} \\
\text { s.t. } & \frac{\sum_{r=1}^{s} u_{r} y_{r j}+\mu_{0}}{\sum_{i=1}^{m} v_{i} x_{i j}+\sum_{t=1}^{l} w_{t}\left(f_{t j}+\delta_{t j}\right)}=1, \quad j=1,2, \cdots, n, \\
& \sum_{j=1}^{n} \delta_{t j}=0, \\
& \alpha_{t j}=\max \left\{\delta_{t j}, 0\right\}, \quad j=1,2, \cdots, n, \\
& f_{t j}+\delta_{t j} \geq 0, \quad j=1,2, \cdots, n, \\
& u_{r}, v_{i}, w_{t} \geq 0 ; \quad \delta_{t j}, \mu_{0} \text { are free. }
\end{array}
$$

Assuming that the optimal solution of the adjustment quantity of the model is $\delta_{t j}^{*}$, then each $\mathrm{DMU}_{j}$ will adjust the fixed-sum output from $f_{t j}$ to $f_{t j}+\delta_{t j}^{*}$, while ensuring that the input and the undesirable fixed-sum output remain unchanged, and the adjusted DMUs are all effective under the constraint conditions. That is, they are all on the front of equilibrium efficiency.

\section{Two-stage Undesirable Fixed-Sum Output DEA Model}

Figure 1 shows the two-stage system structure diagram of undesirable fixed-sum output. Assuming that there are $n \mathrm{DMU}$, each DMU is composed of two stages. In the first stage, $m$ 
initial inputs $x_{i j}(i=1,2, \cdots, m ; j=1,2, \cdots, n)$ are consumed to obtain $B$ desirable outputs $G_{b j}(b=1,2, \cdots, B)$ and $D$ undesirable outputs $Z_{d j}(d=1,2, \cdots, D)$. All the undesirable outputs in the first stage are put into the second stage as inputs, and $q$ exogenous inputs $C_{p j}$ $(p=1,2, \cdots, q)$ are put into the second stage to get $s$ variable-sum output $y_{r j}(r=1,2, \cdots, s)$ and $l$ undesirable fixed-sum output $f_{t j}(t=1,2, \cdots, l)$.

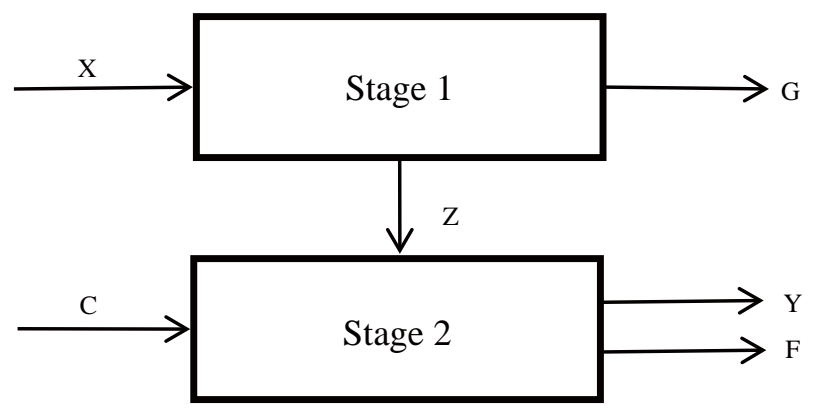

Figure 1 Two-stage system structure diagram of undesirable fixed-sum output

Since there are undesirable fixed-sum outputs in the second stage, we can build an equilibrium efficient frontier based on the GEEFDEA model and evaluate all DMUs on the frontier. In the study of undesirable outputs, the situation of fixed-sum output is very common. Therefore, it is necessary to make the undesirable fixed-sum output constraints into consideration. For industrial water system, opening the "black box" can evaluate the system better, making the evaluation more accurate. Since there are undesirable outputs in the intermediate outputs and final outputs, we hope that as few undesirable outputs as possible, which has the same property as the input. It is used as input when dealing with undesirable outputs. The obtained two-stage undesirable fixed-sum output DEA model as follows:

$$
\begin{array}{ll}
\min & \sum_{j=1}^{n} \sum_{t=1}^{l} w_{t} \alpha_{t j} \\
\text { s.t. } & \frac{\sum_{b=1}^{B} \varphi_{b} G_{b j}+\mu_{0}^{1}}{\sum_{i=1}^{m} v_{i} x_{i j}+\sum_{d=1}^{D} n_{d} Z_{d j}} \leq 1, \quad j=1,2, \cdots, n \\
& \frac{\sum_{r=1}^{s} u_{r} y_{r j}+\mu_{0}^{2}}{\sum_{d=1}^{D} n_{d} Z_{d j}+\sum_{p=1}^{q} \lambda_{p} C_{p j}+\sum_{t=1}^{l} w_{t}\left(f_{t j}+\delta_{t j}\right)}=1, \quad j=1,2, \cdots, n, \\
& \sum_{j=1}^{n} \delta_{t j}=0 \\
& \alpha_{t j}=\max \left\{\delta_{t j}, 0\right\}, \quad j=1,2, \cdots, n \\
& f_{t j}+\delta_{t j} \geq 0, \quad j=1,2, \cdots, n, \\
& u_{r}, v_{i}, w_{t}, n_{d}, \lambda_{p}, \varphi_{b} \geq 0 ; \quad \delta_{t j}, \mu_{0}^{1}, \mu_{0}^{2} \text { are free. }
\end{array}
$$


Set the weight of intermediate output $Z$ in the first and second stages to be consistent ${ }^{[40,41]}$. Since the intermediate output are both the undesirable output of the first stage and the desirable inputs of the second stage, we treat the intermediate output $Z$ as the input of the second stage. Although model (3) requires only one step to construct the equilibrium effective front, the fourth constraint makes model (3) difficult to solve, so we use the following model to replace model (3):

$$
\begin{array}{ll}
\min & \sum_{j=1}^{n} \sum_{t=1}^{l} w_{t}\left|\delta_{t j}\right| \\
\text { s.t. } & \frac{\sum_{b=1}^{B} \varphi_{b} G_{b j}+\mu_{0}^{1}}{\sum_{i=1}^{m} v_{i} x_{i j}+\sum_{d=1}^{D} n_{d} Z_{d j}} \leq 1, \quad j=1,2, \cdots, n \\
& \frac{\sum_{r=1}^{s} u_{r} y_{r j}+\mu_{0}^{2}}{\sum_{d=1}^{D} n_{d} Z_{d j}+\sum_{p=1}^{q} \lambda_{p} C_{p j}+\sum_{t=1}^{l} w_{t}\left(f_{t j}+\delta_{t j}\right)}=1, \quad j=1,2, \cdots, n \\
& \sum_{j=1}^{n} \delta_{t j}=0, \\
& f_{t j}+\delta_{t j} \geq 0, \quad j=1,2, \cdots, n \\
& u_{r}, v_{i}, w_{t}, n_{d}, \lambda_{p}, \varphi_{b} \geq 0 ; \delta_{t j}, \mu_{0}^{1}, \mu_{0}^{2} \text { are free. }
\end{array}
$$

Model (4) is a nonlinear model, so it needs to be transformed into a linear model for solving. This transformation requires two steps: The first step, let $\delta_{t j}^{\prime}=w_{t} \delta_{t j}$ to get the following model (5):

$$
\begin{array}{ll}
\min & \sum_{j=1}^{n} \sum_{t=1}^{l}\left|\delta_{t j}^{\prime}\right| \\
\text { s.t. } & \sum_{b=1}^{B} \varphi_{b} G_{b j}-\sum_{i=1}^{m} v_{i} x_{i j}-\sum_{d=1}^{D} n_{d} Z_{d j}+\mu_{0}^{1} \leq 0, \quad j=1,2, \cdots, n, \\
& \sum_{r=1}^{s} u_{r} y_{r j}-\sum_{d=1}^{D} n_{d} Z_{d j}-\sum_{p=1}^{q} \lambda_{p} C_{p j}-\sum_{t=1}^{l}\left(w_{t} f_{t j}+\delta_{t j}^{\prime}\right)+\mu_{0}^{2}=0, \quad j=1,2, \cdots, n, \\
& \sum_{j=1}^{n} \delta_{t j}^{\prime}=0, \\
& \sum_{d=1}^{D} n_{d} Z_{d j}+\sum_{p=1}^{q} \lambda_{p} C_{p j}+\sum_{t=1}^{l}\left(w_{t} f_{t j}+\delta_{t j}^{\prime}\right) \geq K, \quad j=1,2, \cdots, n, \\
& w_{t} f_{t j}+\delta_{t j}^{\prime} \geq 0, \quad j=1,2, \cdots, n, \\
& u_{r}, v_{i}, w_{t}, n_{d}, \lambda_{p}, \varphi_{b} \geq 0 ; \quad \delta_{t j}^{\prime}, \mu_{0}^{1}, \mu_{0}^{2} \text { are free, }
\end{array}
$$

where $K$ is a given positive constant whose purpose is to ensure that $\sum_{d=1}^{D} n_{d} Z_{d j}+\sum_{p=1}^{q} \lambda_{p} C_{p j}+$ $\sum_{t=1}^{l}\left(w_{t} f_{t j}+\delta_{t j}^{\prime}\right)$ is positive, and here we set $K=1$ to ensure that the target function of the model is positive. The following is the second step of transformation. The transformation process uses the method of $\mathrm{Si}$, et al. ${ }^{[42]}$, let $a_{t j}=\frac{1}{2}\left(\left|\delta_{t j}^{\prime}\right|+\delta_{t j}^{\prime}\right), b_{t j}=\frac{1}{2}\left(\left|\delta_{t j}^{\prime}\right|-\delta_{t j}^{\prime}\right)$ can get 
$\left|\delta_{t j}^{\prime}\right|=a_{t j}+b_{t j}, \delta_{t j}^{\prime}=a_{t j}-b_{t j}$, model (5) can be transformed into the following form:

$$
\begin{array}{ll}
\min & \sum_{j=1}^{n} \sum_{t=1}^{l}\left(a_{t j}+b_{t j}\right) \\
\text { s.t. } & \sum_{b=1}^{B} \varphi_{b} G_{b j}-\sum_{i=1}^{m} v_{i} x_{i j}-\sum_{d=1}^{D} n_{d} Z_{d j}+\mu_{0}^{1} \leq 0, \quad j=1,2, \cdots, n, \\
& \sum_{r=1}^{s} u_{r} y_{r j}-\sum_{d=1}^{D} n_{d} Z_{d j}-\sum_{p=1}^{q} \lambda_{p} C_{p j}-\sum_{t=1}^{l} w_{t} f_{t j}-\sum_{t=1}^{l}\left(a_{t j}-b_{t j}\right)+\mu_{0}^{2}=0, j=1,2, \cdots, n, \\
& \sum_{j=1}^{n}\left(a_{t j}-b_{t j}\right)=0, \\
& \sum_{d=1}^{D} n_{d} Z_{d j}+\sum_{p=1}^{q} \lambda_{p} C_{p j}+\sum_{t=1}^{l} w_{t} f_{t j}+\sum_{t=1}^{l}\left(a_{t j}-b_{t j}\right) \geq K, \quad j=1,2, \cdots, n, \\
& w_{t} f_{t j}+a_{t j}-b_{t j} \geq \pi, \quad j=1,2, \cdots, n, \\
& u_{r}, v_{i}, w_{t}, n_{d}, \lambda_{p}, \varphi_{b}, a_{t j}, b_{t j} \geq 0 ; \quad \mu_{0}^{1}, \mu_{0}^{2} \text { are free. }
\end{array}
$$

Model (6) can construct the equilibrium effective frontier of all DMU in one step. Because of $\delta_{t j}^{*}=a_{t j}^{*}+b_{t j}^{*}$ and $\delta_{t j}^{\prime *}=\sum_{t=1}^{l} w_{t}^{*} \delta_{t j}^{*}$, the undesirable fixed-sum output adjustment can be expressed as

$$
\delta_{t j}^{*}=\frac{\delta_{t j}^{*}}{w_{t}^{*}}=\frac{a_{t j}^{*}-b_{t j}^{*}}{w_{t}^{*}},
$$

and then we can obtain the adjusted output $f_{t j} \delta_{t j}^{*}$.

The following is the evaluation model based on the equilibrium effective frontier. The whole system efficiency is equal to the product of efficiency of two stages to calculate efficiency. The model is as follows:

$$
\begin{array}{ll} 
& e_{k}=\max e_{k}^{1} \times e_{k}^{2} \\
& =\max \frac{\sum_{b=1}^{B} \varphi_{b} G_{b k}+\mu_{0}^{1}}{\sum_{i=1}^{m} v_{i} x_{i k}+\sum_{d=1}^{D} n_{d} Z_{d k}} \times \frac{\sum_{r=1}^{s} u_{r} y_{r k}+\mu_{0}^{2}}{\sum_{d=1}^{D} n_{d} Z_{d k}+\sum_{p=1}^{q} \lambda_{p} C_{p k}+\sum_{t=1}^{l} w_{t} f_{t k}} \\
\text { s.t. } & \frac{\sum_{b=1}^{B} \varphi_{b} G_{b j}+\mu_{0}^{1}}{\sum_{i=1}^{m} v_{i} x_{i j}+\sum_{d=1}^{D} n_{d} Z_{d j}} \leq 1, \quad j=1,2, \cdots, n, \\
& \frac{\sum_{r=1}^{s} u_{r} y_{r j}+\mu_{0}^{2}}{\sum_{d=1}^{D} n_{d} Z_{d j}+\sum_{p=1}^{q} \lambda_{p} C_{p j}+\sum_{t=1}^{l} w_{t}\left(f_{t j}+\delta_{t j}^{*}\right)} \leq 1, \quad j=1,2, \cdots, n, \\
& u_{r}, v_{i}, w_{t}, n_{d}, \lambda_{p}, \varphi_{b} \geq 0 ; \quad \mu_{0}^{1}, \mu_{0}^{2} \text { are free. }
\end{array}
$$

The above model is an input-oriented fractional programming. Due to the existence of free variables and exogenous inputs, it is difficult to transform it into a linear model. Therefore, we use the heuristic search algorithm proposed by Liang, et al. ${ }^{[3]}$ to linearize the model. The heuristic search algorithm fixes the efficiency value of a certain stage in an interval, divide the interval into several parts, and find the optimal overall efficiency value in each DMU. We can fix the efficiency value of the first stage, and obtain the efficiency of the first stage. The model is as follows: 


$$
\begin{aligned}
e_{k}^{1 \mathrm{CCR}}=\max & \frac{\sum_{b=1}^{B} \varphi_{b} G_{b k}+\mu_{0}^{1}}{\sum_{i=1}^{m} v_{i} x_{i k}+\sum_{d=1}^{D} n_{d} Z_{d k}} \\
\text { s.t. } & \frac{\sum_{b=1}^{B} \varphi_{b} G_{b j}+\mu_{0}^{1}}{\sum_{i=1}^{m} v_{i} x_{i j}+\sum_{d=1}^{D} n_{d} Z_{d j}} \leq 1, \quad j=1,2, \cdots, n, \\
& \frac{\sum_{r=1}^{s} u_{r} y_{r j}+\mu_{0}^{2}}{\sum_{d=1}^{D} n_{d} Z_{d j}+\sum_{p=1}^{q} \lambda_{p} C_{p j}+\sum_{t=1}^{l} w_{t}\left(f_{t j}+\delta_{t j}^{*}\right)} \leq 1, \quad j=1,2, \cdots, n, \\
& \mu_{0}^{1}=\mu_{0}^{2}=0, \\
& u_{r}, v_{i}, w_{t}, n_{d}, \lambda_{p}, \varphi_{b} \geq 0 .
\end{aligned}
$$

The optimal objective function value of the model is denoted as $e_{k}^{1 \mathrm{CCR}}$. The first two constraints guarantee that the efficiency value of the two-stage does not exceed 1 . The third constraint indicates that what we measure is CCR efficiency, so the efficiency value of the first stage can be fixed at $\left[0, e_{k}^{1 \mathrm{CCR}}\right]$, that is $e_{k}^{1} \in\left[0, e_{k}^{1 \mathrm{CCR}}\right]$.

Since the interval of efficiency value in the first stage is known, model (7) can be converted into:

$$
\begin{aligned}
e_{k}=\max & e_{k}^{1} \times e_{k}^{2}=\max e_{k}^{1} \times \frac{\sum_{r=1}^{s} u_{r} y_{r k}+\mu_{0}^{2}}{\sum_{d=1}^{D} n_{d} Z_{d k}+\sum_{p=1}^{q} \lambda_{p} C_{p k}+\sum_{t=1}^{l} w_{t} f_{t k}} \\
\text { s.t. } & \frac{\sum_{b=1}^{B} \varphi_{b} G_{b j}+\mu_{0}^{1}}{\sum_{i=1}^{m} v_{i} x_{i j}+\sum_{d=1}^{D} n_{d} Z_{d j}} \leq 1, \quad j=1,2, \cdots, n, \\
& \frac{\sum_{r=1}^{s} u_{r} y_{r j}+\mu_{0}^{2}}{\sum_{d=1}^{D} n_{d} Z_{d j}+\sum_{p=1}^{q} \lambda_{p} C_{p j}+\sum_{t=1}^{l} w_{t}\left(f_{t j}+\delta_{t j}^{*}\right)} \leq 1, \quad j=1,2, \cdots, n, \\
& e_{k}^{1}=\frac{\sum_{b=1}^{B} \varphi_{b} G_{b k}+\mu_{0}^{1}}{\sum_{i=1}^{m} v_{i} x_{i k}+\sum_{d=1}^{D} n_{d} Z_{d k}}, \\
& e_{k}^{1} \in\left[0, e_{k}^{1 C C R}\right], \\
& u_{r}, v_{i}, w_{t}, n_{d}, \lambda_{p}, \varphi_{b} \geq 0 ; \quad \mu_{0}^{1}, \mu_{0}^{2} \text { are free. }
\end{aligned}
$$

the model can be transformed into the following model through C-C transformation:

$$
\begin{aligned}
& e_{k}=\max e_{k}^{1} \times e_{k}^{2}=\max e_{k}^{1} \times \sum_{r=1}^{s} u_{r} y_{r k}+\mu_{0}^{2} \\
\text { s.t. } & \sum_{b=1}^{B} \varphi_{b} G_{b j}+\mu_{0}^{1}-\sum_{i=1}^{m} v_{i} x_{i j}-\sum_{d=1}^{D} n_{d} Z_{d j} \leq 0, \quad j=1,2, \cdots, n, \\
& \sum_{r=1}^{s} u_{r} y_{r j}+\mu_{0}^{2}-\sum_{d=1}^{D} n_{d} Z_{d j}-\sum_{p=1}^{q} \lambda_{p} C_{p j}-\sum_{t=1}^{l} w_{t}\left(f_{t j}+\delta_{t j}^{*}\right) \leq 0, j=1,2, \cdots, n, \\
& \sum_{b=1}^{B} \varphi_{b} G_{b k}+\mu_{0}^{1}-e_{k}^{1} \times \sum_{i=1}^{m} v_{i} x_{i k}-e_{k}^{1} \times \sum_{d=1}^{D} n_{d} Z_{d k}=0, \\
& \sum_{d=1}^{D} n_{d} Z_{d k}+\sum_{p=1}^{q} \lambda_{p} C_{p k}+\sum_{t=1}^{l} w_{t} f_{t k}=1, \\
& e_{k}^{1} \in\left[0, e_{k}^{1 \mathrm{CCR}}\right], \\
& u_{r}, v_{i}, w_{t}, n_{d}, \lambda_{p}, \varphi_{b} \geq 0 ; \mu_{0}^{1}, \mu_{0}^{2} \text { are free. }
\end{aligned}
$$


Model (10) is the final efficiency evaluation model. In order to calculate the optimal solution of the model, let $e_{k}^{1}=e_{k}^{1 \mathrm{CCR}}-t \varepsilon$, and $\varepsilon$ be the step size of the heuristic search algorithm. The smaller the step size is, the more accurate the result will be. Let $\varepsilon=0.005, t=0,1, \cdots,\left[t_{\max }\right]+$ 1 , where $\left[t_{\max }\right]$ is the largest integer value that $\frac{e_{k}^{1 \mathrm{CCR}}}{\varepsilon}$ can obtain, when $t$ increases from 0 to $\left[t_{\max }\right]+1$. For each $t$, we have a $e_{k}^{1}(t)$, and the global optimal solution corresponding to each $t$ is denoted as $e_{k}(t)$, then the global optimal solution of the total efficiency of the whole two-stage system is $e_{k}^{*}=\max e_{k}(t)$. At the same time, the efficiency value of the first stage is $e_{k}^{1}=e_{k}^{1}\left(t^{*}\right)=e_{k}^{1 \mathrm{CCR}}-t^{*} \varepsilon$, where $t^{*}=\min \left\{t \mid e_{k}^{*}=e_{k}(t)\right\}$. Therefore, the corresponding efficiency value of the second stage is $e_{k}^{2}=\frac{e_{k}^{*}}{e_{k}^{1}}$, then $e_{k}^{*}=\max e_{k}^{1} \times e_{k}^{2}$. We get the global optimal solution and the unique two-stage decomposition efficiency.

\section{Application in China's Regional Industrial System}

\subsection{Indicators and Data Sources}

The development of industry will bring serious water pollution. We divide the industrial system of China's 30 provinces into two stages. The first stage is industrial water utilization stage and the second stage is pollutant treatment stage. The specific structure is shown in Figure 2 .

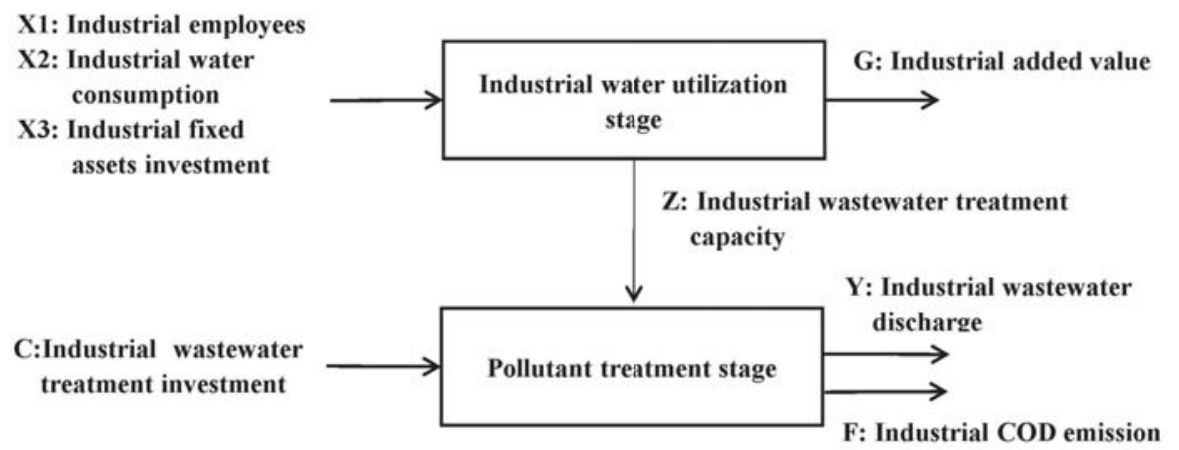

Figure 2 Two-stage structure of industrial production system

With the emphasis on ecological environment, many scholars began to apply DEA method to evaluate the utilization efficiency of water resources in China. For example, based on the two-stage SBM model of undesirable output, Ren, et al. selected water resources, capital, labor and additional pollutant treatment investment as input indicators, GDP, COD and AN as output indicators to analyze the efficiency of inter provincial water resources in China ${ }^{[44]}$. Xie, et al. used industrial water consumption, power consumption, labor, industrial pollution and wastewater treatment investment as input indicators, industrial wastewater COD emission and total industrial output value as output indicators, and used DEA to allocate wastewater emission $^{[45]}$. In addition, there are many studies on input-output indicators of water resources utilization $^{[46-50]}$.

In this paper, according to previous studies on the utilization of water resources, the inputoutput indicators select the industrial employees, industrial water consumption and industrial fixed assets investment as input indicators in industrial water utilization stage. Industrial added value can directly reflect the economic value brought by industrial water utilization stage, so 
it is regarded as desirable output. Industrial wastewater treatment capacity is regarded as undesirable output, and we treat it as input in the pollutant treatment stage. When the generated industrial wastewater treatment capacity is treated in the pollutant treatment stage, we take the industrial wastewater treatment capacity as input index. In addition, the industrial wastewater treatment investment is exogenous input, and the industrial wastewater discharge and industrial COD emission are undesirable outputs, in which the industrial COD emission is fixed-sum output.

Since the National Bureau of statistics stopped publishing the data of industrial wastewater treatment capacity and industrial COD emission after 2015. In this section, the two-stage undesirable fixed-sum output DEA model proposed in this paper is applied to analyze the environmental efficiency of industrial water system in 30 provinces during the 12th Five Year Plan (2011-2015) to verify the rationality of the proposed model. The index data of industrial employees, industrial water consumption, industrial fixed assets investment and industrial added value are from the "China Statistical Yearbook" (2011-2015), and the relevant data of industrial wastewater treatment investment, industrial wastewater discharge, industrial wastewater treatment capacity and industrial COD emission are from the "China Environmental Statistical Yearbook" (2011-2015). The relevant descriptions of the inputs and outputs of the industrial water system in each province are shown in Table 1.

Table 1 Descriptive statistical analysis results of original data

\begin{tabular}{|c|c|c|c|c|c|c|c|}
\hline Category & Stage & Variable & Unit & Mean & $\begin{array}{l}\text { Std. } \\
\text { Dev }\end{array}$ & Max & Min \\
\hline \multirow{4}{*}{ Inputs } & 1 & Industrial employees & $\begin{array}{l}10,000 \\
\text { persons }\end{array}$ & 192.1 & 182.3 & 1055.4 & 11.4 \\
\hline & 1 & $\begin{array}{l}\text { Industrial water } \\
\text { consumption }\end{array}$ & $\begin{array}{l}\text { Billion cubic } \\
\text { meters }\end{array}$ & 46.5 & 45.4 & 239.0 & 2.4 \\
\hline & 1 & $\begin{array}{l}\text { Industrial fixed assets } \\
\text { investment }\end{array}$ & $\begin{array}{l}100 \text { million } \\
\text { yuan }\end{array}$ & 5898.2 & 4681.5 & 23302.0 & 245.1 \\
\hline & 2 & $\begin{array}{l}\text { Industrial wastewater } \\
\text { treatment investment }\end{array}$ & 10,000 yuan & 43649.1 & 45451.9 & 295540.0 & 90.0 \\
\hline $\begin{array}{l}\text { Desirable } \\
\text { output }\end{array}$ & 1 & Industrial added value & $\begin{array}{l}100 \text { million } \\
\text { yuan }\end{array}$ & 8646.7 & 6916.5 & 30259.5 & 472.4 \\
\hline \multirow[t]{2}{*}{$\begin{array}{l}\text { Undesirable } \\
\text { output }\end{array}$} & & $\begin{array}{l}\text { Industrial wastewater } \\
\text { discharge }\end{array}$ & 10,000 tons & 71129.2 & 56843.2 & 246298.0 & 6744.0 \\
\hline & 2 & $\begin{array}{l}\text { Industrial COD } \\
\text { emission }\end{array}$ & tons & 107805.8 & 59734.0 & 243959.0 & 4738.0 \\
\hline $\begin{array}{l}\text { Join } \\
\text { variable }\end{array}$ & $1 \sim 2$ & $\begin{array}{l}\text { Industrial wastewater } \\
\text { treatment capacity }\end{array}$ & 10,000 tons & 169638.1 & 160182.9 & 933519.0 & 6474.0 \\
\hline
\end{tabular}




\subsection{Analysis of Regional Differences}

China's Seventh Five Year Plan (1986-1990) proposed to divide the country into three major economic regions, namely eastern, central and western regions. Industrial water can bring economic benefits. Due to the difference of geographical location, the distribution of water resources in various regions of China is not balanced. In Table 2, the efficiency values of the whole system from 2011 to 2015 are listed according to the method we proposed, and compared with the BCC efficiency. BCC model is used to measure pure technology and scale efficiency, assuming that DMU is in variable return to scale. But BCC model regards the industrial water system as a "black box", it is using the initial input and final output calculation efficiency value, ignoring system internal structure, which greatly reduces the recognition of inefficient DMU in the system. This paper open the black box, makes the evaluation of DMU more accurate and reasonable. In terms of overall efficiency, among the 11 provinces in the eastern region: Beijing, Tianjin, Shanghai and Hainan are effective, only Jilin is effective in the central region, and Inner Mongolia, Chongqing, Guizhou, Shaanxi and Qinghai are effective in the western region.

Among the 30 provinces, Beijing has the highest efficiency, which is 24.75, and Jiangsu has the lowest efficiency, which is 0.02. In Table 3, we can analyze the reasons for the efficiency difference from the efficiency values of the two stages. Beijing ranks first in the efficiency value in both stages. In the first stage, due to the development of industrial technology and efficient water facilities, water resources have been fully utilized. In the second stage, Beijing has little industrial wastewater treatment capacity, little investment in wastewater treatment, and the industrial COD emission is the lowest among the 30 provinces, so it has high efficiency in the second stage. The efficiency of Jiangsu province in the first stage is 0.79 , and the efficiency in the second stage is 0.03 , ranking 30. Due to the rapid economic development of coastal areas in Jiangsu, most industrial enterprises not only brings economic benefits, but also produces a lot of industrial wastewater, and a large amount of COD emission. Among them, cotton and chemical fiber products manufacturing and other traditional industries have the largest industrial COD emission intensity, which causes great ecological damage and low efficiency in the second stage. It shows that the growth of economic scale is accompanied by the pressure of pollutant emission. Comparing the two stages efficiency with the overall efficiency, we can find that the overall efficiency is more inclined to the efficiency value of pollutant treatment stage, which shows that the second stage plays a decisive role in the whole system. Excessive industrial COD emission and insufficient treatment in various regions will lead to low overall efficiency, which also reflects the importance of pollutant treatment in the industrial system.

Comparing the efficiency values of the eastern, central and western regions from Table 3, there are 15 regions with the efficiency value of $0.8 \sim 1$ in the first stage, which are efficient in the industrial system. Among them, Beijing, Tianjin, Shanghai and Inner Mongolia are effective in the first stage, indicating that these four provinces have reached the best state in the first stage, and the input-output structure is reasonable. Among the five-year average efficiency, the three provinces with the lowest efficiency in the first stage are Ningxia, Gansu and Xinjiang, which are $0.56,0.61$ and 0.62 , respectively. There are great room for improvement in the industrial water utilization efficiency, so these provinces should pay more attention to the distribution of water resources in the future. In the past five years, the first stage efficiency of 30 provinces in 
Table 2 Efficiency of industrial system in different provinces from 2011 to 2015

\begin{tabular}{|c|c|c|c|c|c|c|c|c|c|c|c|c|}
\hline \multirow[b]{2}{*}{ Region } & \multicolumn{6}{|c|}{ Overall efficiency } & \multicolumn{6}{|c|}{ BCC efficiency } \\
\hline & 2011 & 2012 & 2013 & 2014 & 2015 & average & 2011 & 2012 & 2013 & 2014 & 2015 & average \\
\hline Beijing & 22.94 & 24.76 & 23.70 & 24.09 & 28.27 & 724.75 & 1.00 & 1.00 & 1.00 & 1.00 & 1.00 & 1.00 \\
\hline Tianjin & 6.42 & 5.60 & 5.37 & 4.91 & 4.54 & 5.37 & 1.00 & 1.00 & 1.00 & 1.00 & 1.00 & 1.00 \\
\hline Hebei & 0.47 & 0.42 & 0.46 & 0.42 & 0.55 & 0.46 & 1.00 & 0.99 & 1.00 & 0.95 & 1.00 & 0.99 \\
\hline Liaoning & 0.87 & 0.90 & 1.05 & 0.93 & 1.02 & 0.96 & 0.92 & 1.00 & 0.98 & 0.96 & 1.00 & 0.97 \\
\hline Shanghai & 5.10 & 5.00 & 4.82 & 4.89 & 4.73 & 4.91 & 1.00 & 1.00 & 1.00 & 1.00 & 1.00 & 1.00 \\
\hline Jiangsu & 0.02 & 0.02 & 0.02 & 0.03 & 0.02 & 0.02 & 0.91 & 1.00 & 0.79 & 0.74 & 0.74 & 0.84 \\
\hline Zhejiang & 0.23 & 0.21 & 0.24 & 0.26 & 0.27 & 0.24 & 0.90 & 0.84 & 0.94 & 0.92 & 0.97 & 0.91 \\
\hline Fujian & 0.29 & 0.57 & 0.76 & 0.80 & 0.81 & 0.64 & 0.59 & 0.62 & 0.76 & 0.77 & 0.79 & 0.71 \\
\hline Shandong & 0.32 & 0.27 & 0.21 & 0.16 & 0.13 & 0.22 & 0.99 & 0.92 & 0.87 & 0.87 & 0.89 & 0.91 \\
\hline Guangdong & 0.21 & 0.16 & 0.14 & 0.09 & 0.12 & 0.14 & 1.00 & 1.00 & 1.00 & 0.79 & 0.77 & 0.91 \\
\hline Hainan & 9.54 & 8.75 & 8.06 & 10.11 & 13.03 & 9.90 & 1.00 & 1.00 & 1.00 & 1.00 & 1.00 & 1.00 \\
\hline Eastern & 4.22 & 4.24 & 4.08 & 4.24 & 4.86 & 4.33 & 0.94 & 0.94 & 0.94 & 0.91 & 0.92 & 0.93 \\
\hline Shanxi & 1.31 & 1.03 & 0.94 & 0.89 & 0.75 & 0.99 & 0.84 & 0.69 & 0.62 & 0.55 & 0.46 & 0.63 \\
\hline Jilin & 1.48 & 1.28 & 1.57 & 1.52 & 1.53 & 1.47 & 0.89 & 1.00 & 0.98 & 1.00 & 0.86 & 0.95 \\
\hline Heilongjiang & 1.00 & 0.85 & 0.89 & 0.95 & 0.82 & 0.90 & 0.85 & 1.00 & 0.74 & 0.84 & 0.64 & 0.81 \\
\hline Anhui & 0.93 & 0.98 & 0.97 & 1.03 & 0.78 & 0.94 & 0.94 & 1.00 & 0.98 & 0.88 & 0.88 & 0.93 \\
\hline Jiangxi & 0.66 & 0.72 & 0.75 & 0.87 & 0.55 & 0.71 & 0.85 & 0.84 & 0.69 & 0.68 & 0.61 & 0.73 \\
\hline Henan & 0.33 & 0.32 & 0.26 & 0.24 & 0.22 & 0.27 & 0.99 & 0.99 & 0.68 & 0.63 & 0.64 & 0.79 \\
\hline Hubei & 0.49 & 0.57 & 0.57 & 0.59 & 0.54 & 0.55 & 0.79 & 0.85 & 0.90 & 0.84 & 0.85 & 0.84 \\
\hline Hunan & 0.49 & 0.55 & 0.61 & 0.69 & 0.62 & 0.59 & 0.80 & 0.85 & 0.93 & 0.98 & 0.96 & 0.90 \\
\hline Central & 0.83 & 0.79 & 0.82 & 0.85 & 0.73 & 0.80 & 0.87 & 0.90 & 0.81 & 0.80 & 0.74 & 0.82 \\
\hline Inner Mongolia & 1.55 & 1.53 & 1.39 & 1.25 & 1.21 & 1.39 & 1.00 & 1.00 & 1.00 & 1.00 & 1.00 & 1.00 \\
\hline Guangxi & 0.43 & 0.36 & 0.45 & 0.55 & 0.54 & 0.47 & 0.86 & 0.81 & 0.84 & 0.89 & 0.94 & 0.87 \\
\hline Chongqing & 2.53 & 2.68 & 2.08 & 1.96 & 2.09 & 2.27 & 0.86 & 0.92 & 0.89 & 0.94 & 0.89 & 0.90 \\
\hline Sichuan & 0.75 & 0.86 & 0.91 & 0.92 & 0.81 & 0.85 & 0.84 & 0.90 & 0.88 & 0.93 & 0.88 & 0.88 \\
\hline Guizhou & 1.20 & 1.24 & 1.55 & 1.52 & 1.71 & 1.44 & 0.92 & 0.63 & 0.75 & 0.81 & 0.89 & 0.80 \\
\hline Yunnan & 0.46 & 0.46 & 0.51 & 0.54 & 0.54 & 0.50 & 0.60 & 0.61 & 0.69 & 0.72 & 0.71 & 0.67 \\
\hline Shaanxi & 1.31 & 1.35 & 1.20 & 1.18 & 0.86 & 1.18 & 0.99 & 0.97 & 0.88 & 0.89 & 0.80 & 0.91 \\
\hline Gansu & 1.20 & 1.03 & 0.92 & 0.93 & 0.77 & 0.97 & 0.67 & 0.67 & 0.64 & 0.60 & 0.55 & 0.63 \\
\hline Qinghai & 3.00 & 2.91 & 2.44 & 2.59 & 2.15 & 2.62 & 1.00 & 1.00 & 1.00 & 1.00 & 1.00 & 1.00 \\
\hline Ningxia & 0.83 & 0.79 & 0.81 & 0.83 & 0.95 & 0.84 & 0.78 & 0.74 & 0.79 & 0.74 & 0.76 & 0.76 \\
\hline Xinjiang & 0.55 & 0.51 & 0.43 & 0.44 & 0.34 & 0.45 & 0.72 & 0.67 & 0.66 & 0.65 & 0.58 & 0.66 \\
\hline Western & 1.25 & 1.25 & 1.15 & 1.15 & 1.09 & 1.18 & 0.84 & 0.81 & 0.82 & 0.83 & 0.82 & 0.82 \\
\hline National & 2.23 & 2.22 & 2.14 & 2.21 & 2.38 & 2.23 & 0.88 & 0.88 & 0.86 & 0.85 & 0.84 & 0.86 \\
\hline
\end{tabular}


Table 3 Efficiency of water utilzation and treatment in 30 provinces of China from 2011 to 2015

\begin{tabular}{|c|c|c|c|c|c|c|c|c|c|c|c|c|}
\hline \multirow[b]{2}{*}{ Region } & \multicolumn{6}{|c|}{ Stage 1 efficiency } & \multicolumn{6}{|c|}{ Stage 2 efficiency } \\
\hline & 2011 & 2012 & 2013 & 2014 & 2015 & average & 2011 & 2012 & 2013 & 2014 & 2015 & average \\
\hline Beijing & 1.00 & 1.00 & 1.00 & 1.00 & 1.00 & 1.00 & 22.94 & 24.76 & 23.70 & 24.09 & 28.27 & 24.75 \\
\hline Tianjin & 1.00 & 1.00 & 1.00 & 1.00 & 1.00 & 1.00 & 6.42 & 5.60 & 5.37 & 4.91 & 4.54 & 5.37 \\
\hline Hebei & 1.00 & 0.99 & 1.00 & 0.95 & 0.93 & 0.97 & 0.47 & 0.42 & 0.46 & 0.45 & 0.60 & 0.48 \\
\hline Liaoning & 0.88 & 0.89 & 0.88 & 0.90 & 0.93 & 0.90 & 0.99 & 1.02 & 1.19 & 1.03 & 1.10 & 1.07 \\
\hline Shanghai & 1.00 & 1.00 & 1.00 & 1.00 & 1.00 & 1.00 & 5.10 & 5.00 & 4.82 & 4.89 & 4.73 & 4.91 \\
\hline Jiangsu & 0.84 & 0.88 & 0.79 & 0.74 & 0.72 & 0.79 & 0.03 & 0.03 & 0.03 & 0.03 & 0.03 & 0.03 \\
\hline Zhejiang & 0.90 & 0.84 & 0.94 & 0.92 & 0.97 & 0.91 & 0.26 & 0.25 & 0.25 & 0.28 & 0.28 & 0.26 \\
\hline Fujian & 0.54 & 0.57 & 0.76 & 0.77 & 0.78 & 0.68 & 0.54 & 1.01 & 1.00 & 1.03 & 1.04 & 0.92 \\
\hline Shandong & 0.99 & 0.92 & 0.86 & 0.85 & 0.85 & 0.89 & 0.32 & 0.29 & 0.24 & 0.19 & 0.15 & 0.24 \\
\hline Guangdong & 1.00 & 1.00 & 0.82 & 0.78 & 0.77 & 0.87 & 0.21 & 0.16 & 0.17 & 0.11 & 0.16 & 0.16 \\
\hline Hainan & 0.72 & 0.70 & 0.68 & 0.74 & 0.84 & 0.74 & 13.16 & 12.46 & 11.93 & 13.59 & 15.53 & 13.33 \\
\hline Eastern & 0.90 & 0.89 & 0.88 & 0.88 & 0.89 & 0.89 & 4.58 & 4.64 & 4.47 & 4.60 & 5.13 & 4.68 \\
\hline Shanxi & 0.84 & 0.69 & 0.62 & 0.55 & 0.45 & 0.63 & 1.57 & 1.50 & 1.53 & 1.62 & 1.64 & 1.57 \\
\hline Jilin & 0.82 & 0.74 & 0.82 & 0.83 & 0.81 & 0.80 & 1.80 & 1.73 & 1.92 & 1.84 & 1.88 & 1.83 \\
\hline Heilongjiang & 0.73 & 0.68 & 0.70 & 0.73 & 0.64 & 0.70 & 1.37 & 1.25 & 1.27 & 1.30 & 1.29 & 1.30 \\
\hline Anhui & 0.71 & 0.75 & 0.79 & 0.82 & 0.68 & 0.75 & 1.30 & 1.31 & 1.22 & 1.26 & 1.15 & 1.25 \\
\hline Jiangxi & 0.63 & 0.62 & 0.65 & 0.65 & 0.56 & 0.62 & 1.04 & 1.16 & 1.15 & 1.33 & 0.99 & 1.14 \\
\hline Henan & 0.82 & 0.81 & 0.67 & 0.63 & 0.58 & 0.70 & 0.40 & 0.40 & 0.39 & 0.39 & 0.38 & 0.39 \\
\hline Hubei & 0.70 & 0.76 & 0.76 & 0.78 & 0.72 & 0.74 & 0.69 & 0.75 & 0.76 & 0.75 & 0.75 & 0.74 \\
\hline Hunan & 0.80 & 0.85 & 0.93 & 0.98 & 0.85 & 0.88 & 0.61 & 0.65 & 0.65 & 0.70 & 0.74 & 0.67 \\
\hline Central & 0.76 & 0.74 & 0.74 & 0.75 & 0.66 & 0.73 & 1.10 & 1.09 & 1.11 & 1.15 & 1.10 & 1.11 \\
\hline Inner Mongolia & 1.00 & 1.00 & 1.00 & 1.00 & 1.00 & 1.00 & 1.55 & 1.53 & 1.39 & 1.25 & 1.21 & 1.39 \\
\hline Guangxi & 0.86 & 0.81 & 0.84 & 0.89 & 0.78 & 0.83 & 0.50 & 0.44 & 0.53 & 0.62 & 0.69 & 0.56 \\
\hline Chongqing & 1.00 & 0.93 & 0.82 & 0.82 & 0.88 & 0.89 & 2.53 & 2.87 & 2.55 & 2.39 & 2.37 & 2.54 \\
\hline Sichuan & 0.83 & 0.89 & 0.88 & 0.93 & 0.88 & 0.88 & 0.90 & 0.97 & 1.03 & 0.99 & 0.92 & 0.96 \\
\hline Guizhou & 0.50 & 0.55 & 0.71 & 0.79 & 0.85 & 0.68 & 2.37 & 2.25 & 2.18 & 1.92 & 2.00 & 2.15 \\
\hline Yunnan & 0.58 & 0.59 & 0.68 & 0.71 & 0.70 & 0.65 & 0.79 & 0.78 & 0.75 & 0.76 & 0.76 & 0.77 \\
\hline Shaanxi & 0.98 & 0.98 & 0.88 & 0.89 & 0.80 & 0.91 & 1.33 & 1.38 & 1.35 & 1.32 & 1.08 & 1.29 \\
\hline Gansu & 0.74 & 0.64 & 0.60 & 0.59 & 0.49 & 0.61 & 1.62 & 1.60 & 1.55 & 1.56 & 1.57 & 1.58 \\
\hline Qinghai & 0.75 & 0.78 & 0.69 & 0.73 & 0.63 & 0.72 & 4.02 & 3.71 & 3.52 & 3.54 & 3.40 & 3.64 \\
\hline Ningxia & 0.59 & 0.55 & 0.58 & 0.58 & 0.49 & 0.56 & 1.40 & 1.43 & 1.39 & 1.42 & 1.94 & 1.51 \\
\hline Xinjiang & 0.68 & 0.67 & 0.62 & 0.64 & 0.50 & 0.62 & 0.80 & 0.76 & 0.70 & 0.69 & 0.68 & 0.73 \\
\hline Western & 0.77 & 0.76 & 0.75 & 0.78 & 0.73 & 0.76 & 1.62 & 1.61 & 1.54 & 1.50 & 1.51 & 1.56 \\
\hline National & 0.81 & 0.80 & 0.80 & 0.81 & 0.77 & 0.80 & 2.57 & 2.58 & 2.50 & 2.54 & 2.73 & 2.58 \\
\hline
\end{tabular}


China has shown differences. Most of the provinces with high efficiency are concentrated in the eastern region. The average value of the first stage efficiency in the eastern region is 0.89 , in the central region is 0.73 , and in the western region is 0.76 . They have not achieved effective efficiency, but they are greater than 0.7 .

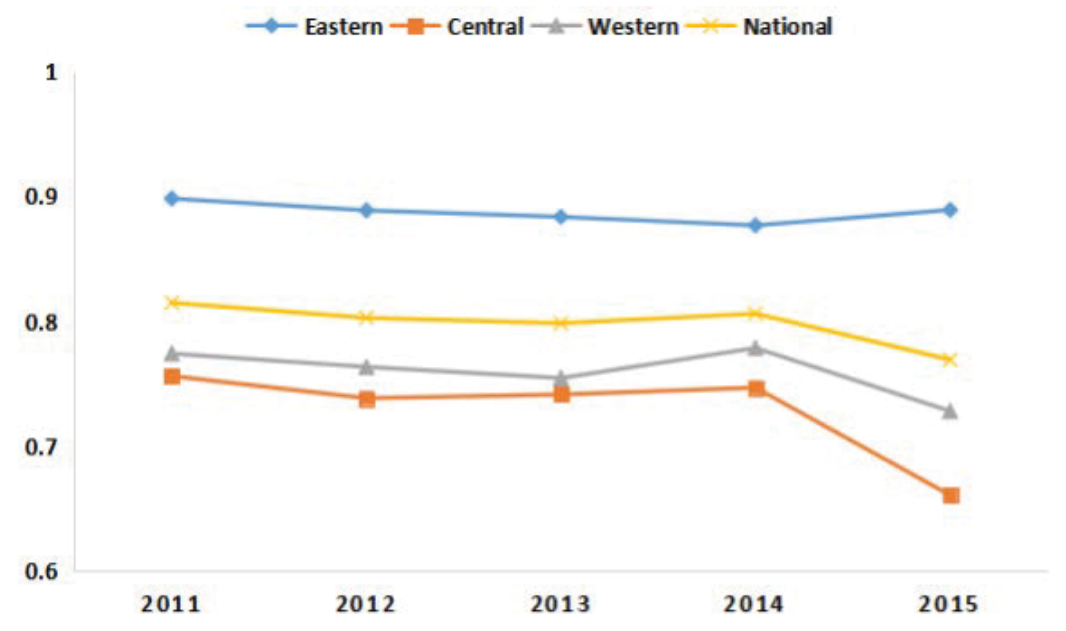

Figure 3 Average efficiency of industrial water utilization in 2011-2015

Figure 3 demonstrate that the difference of the first stage efficiency between the eastern, central and western regions of China from 2011 to 2015. The eastern region has the highest efficiency and the central region has the lowest efficiency. This is because the eastern region is mostly coastal provinces, with relatively concentrated industries and developed economy, and pays more attention to the introduction of technology. Due to better resources and jobs in the eastern region, China's labor force is gradually concentrated from the central and western regions to the eastern region, and a large number of excellent talents are introduced. At the same time, the awareness of environmental protection is stronger than that of the central and western regions, the industrial development is relatively mature, and more attention is paid to the recycling of industrial water, which is conducive to the improvement of industrial water efficiency. Due to the difference of geographical location, the development level of central region is relatively backward. In order to accelerate economic development and improve GDP, the emission of industrial wastewater increases significantly, resulting in waste of water resources and low input-output benefits. Compared with the eastern and central regions, the western region mainly develops the local economy by rough processing mineral resources and heavy industry. The technical level is low, water resources are scarce, and the protection of water resources is not enough. The production and processing is mainly extensive, resulting in low efficiency. However, the efficiency in Inner Mongolia has been effective, due to there are few large-scale production enterprises in Inner Mongolia, the output and investment are low, and the water use structure is relatively reasonable, so it can achieve effective.

The second stage is the pollutant treatment stage. Regarding industrial COD emission as undesirable fixed-sum output, but we treat it as input in the model, which is more in line with 
the objective fact of input-oriented. Among them, there are 5 effective areas in the eastern, namely Beijing, Tianjin, Liaoning, Shanghai and Hainan. There are 5 effective areas in the middle, namely Shanxi, Jilin, Heilongjiang, Anhui and Jiangxi. There are 7 effective areas in the western, namely Inner Mongolia, Chongqing, Guizhou, Shaanxi, Gansu, Qinghai and Ningxia. Due to the high efficiency of Beijing and Hainan in the second stage (the average efficiency of Beijing is 24.75 and Hainan is 9.9), the average efficiency of the eastern region is 4.68 , which is a relatively high efficiency value.

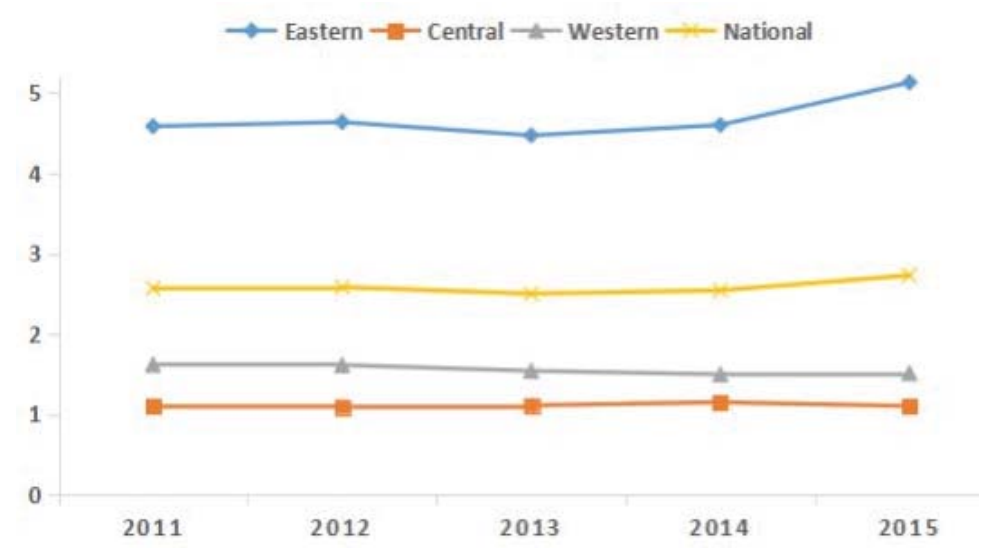

Figure 4 Average efficiency of pollutant treatment stage from 2011 to 2015

Figure 4 demonstrates that the efficiency values of the pollutant treatment stage in the eastern region reached the lowest in 2013, which is 4.47 , and then increased significantly, reaching the maximum in 2015. The average efficiency value of the central region is 1.11 , and the average efficiency value of the western region is 1.56 . We observe that the pollutant treatment stage shows the characteristics related to geographical location in different regions, which is also closely related to national policies. In October 2010, the State Council promulgated "the Decision of the State Council on Accelerating the Cultivation and Development of Strategic Emerging Industries", which regarded energy conservation and environmental protection as one of the seven strategic emerging industries. In April 2015, the State Council promulgated the "Water Pollution Prevention and Control Action Plan" (the "Ten Articles on Water"), supervised industrial wastewater treatment for the first time, and issued the notice on energy conservation and emission reduction in the "12th Five Year Plan", "13th Five Year Plan", which shows that while vigorously developing the economy, China has begun to pay attention to the protection of environmental resources. Under the national policy, China's wastewater treatment technology has also been greatly improved, and gradually realize the coordinated development of economy and environmental protection.

These results demonstrate that for different provinces, the industrial water utilization and pollution treatment efficiency showed different trends from 2011 to 2015. Industrial system efficiency is the product of industrial water utilization and pollutant treatment efficiency, and the average value of overall efficiency in most regions is between the average efficiency values of the two stages, indicating that China's industrial system efficiency is affected by the efficiency of the two stages. In Table 2, we list the efficiency values that treat each province as a "black 
box". We compare the average efficiency of fixed-sum output of each province in the two stages from 2011 to 2015 with the average efficiency of BCC. There are 6 effective regions in BCC efficiency, namely Beijing, Tianjin, Shanghai, Hainan, Inner Mongolia and Qinghai. Their efficiency values are all 1 . It is impossible to effectively rank to judge who is more efficient. The two-stage undesirable fixed-sum output DEA model can rank effective DMUs, that is, the higher the efficiency, the higher the ranking.

Through the two-stage undesirable fixed-sum output DEA model proposed in this paper, we can analyze the reasons for the low efficiency of each province and put forward effective improvement schemes. As shown in Figure 5, the average environmental efficiency of the two stages is used to draw the efficiency matrix. The horizontal axis of the efficiency matrix represents the efficiency of the industrial water utilization stage, and the vertical axis represents the efficiency of the pollutant treatment stage ${ }^{[51]}$. The matrix is divided into four quadrants, each province is in four quadrants, of which the average efficiency of the industrial water utilization stage is 0.8 , The average efficiency of pollutant treatment stage is 2.58 . We can put forward suggestions and policies to improve environmental efficiency according to the location of each province. Provinces in the first quadrant have high efficiency values in both water utilization stage and pollutant treatment stage. Beijing, Tianjin and Shanghai are in the first quadrant, which perform well in both stages. Hainan and Qinghai are in the second quadrant. Provinces in this quadrant have low efficiency in water utilization stage and high efficiency in pollutant treatment stage, Shanxi, Heilongjiang, Jiangsu, Anhui, Fujian, Jiangxi, Henan, Hubei, Guizhou, Yunnan, Gansu, Ningxia and Xinjiang are in the third quadrant, these provinces in this quadrant have low efficiency in both stages. Hebei, Inner Mongolia, Liaoning, Jilin, Zhejiang, Shandong, Hunan, Guangdong, Guangxi, Chongqing, Sichuan and Shaanxi are in the fourth quadrant, these provinces have high efficiency in the water utilization stage and low efficiency in the pollutant treatment stage. For example, Hebei has high efficiency in the water utilization stage, but it does not reach the average value in the pollutant treatment stage. If we want to improve the efficiency in the whole system, we should increase investment in the pollutant treatment stage and pay more attention to environmental protection while accelerating economic development.

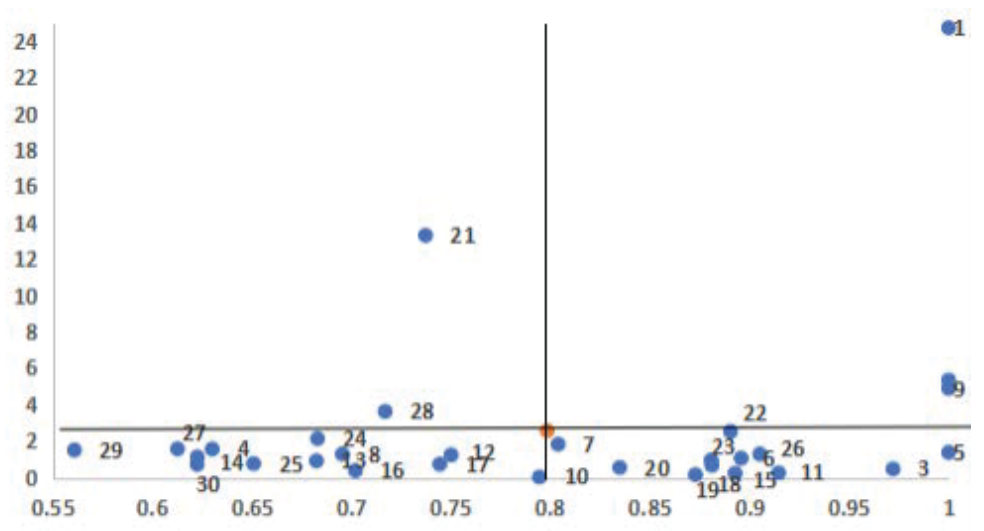

Figure 5 Environmental efficiency description of two stages 
Comparing the two-stage overall efficiency values of 30 provinces according to the eastern, central and western regions with the national efficiency. The eastern region has the best efficiency in the industrial water system is presented in Figure 6. Most of the eastern regions are coastal regions, with relatively perfect infrastructure, developed industrial industries and advanced water equipment, which is higher than the resource allocation in the central and western regions. Due to the backward economy, the number of industrial enterprises above designated size in the western region is far less than that in the eastern region, and many regions are dominated by tourism, the industrialization level is relatively low, which makes the industrial COD emission lower than that in the eastern and central regions. The central region is in a period of vigorous development. In order to drive the national economic development, industry is the largest industry. With the development of industry, the output increases and the pollutant emission is becoming more and more serious. In the pursuit of economy, the treatment of industrial wastewater is particularly important. While pursuing economic development, the central region should introduce advanced water-saving and emission reduction technologies to ensure the synchronous development of economy and environment.

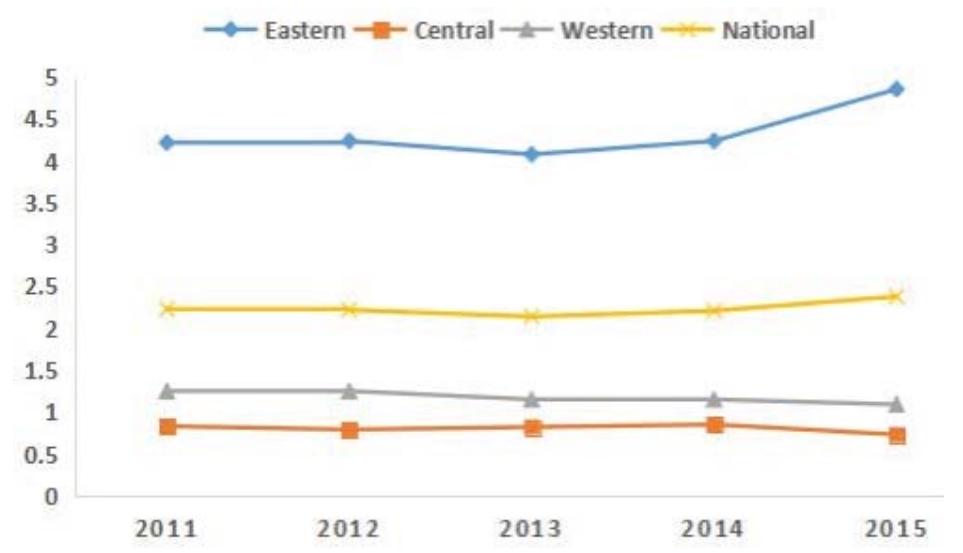

Figure 6 Line chart of system efficiency in different regions

\section{Conclusions and Policy Recommendations}

The level of industrialization represents the speed of a country's economic development, and the ecological environment determines whether the industrialization development can be longterm. Since the reform and opening-up, China has taken economic construction as the center and vigorously developed productive forces. Up to now, China has established the concept of sustainable development precisely because China has realized that it can not exchange economic growth at the cost of consuming resources and destroying the ecological environment. In the production process, apart from the desirable output generated by the treatment consumption input, it also produce undesirable output. The state has restricted the emission of COD in industrial wastewater. Therefore, it seems reasonable to fix the annual industrial COD emission in the current environment efficiency analysis of the 30 provinces and cities. The traditional DEA model regards the industrial water system as a "black box", does not consider the internal structure, can only analyze the efficiency of the whole system from the initial input and final 
output. With the understanding of the interior of industrial water system, a DEA model with two-stage network structure is proposed. The method proposed in this paper can identify inefficient provinces, provide more accurate information for decision-makers, facilitate decisionmakers to put forward improvement policies and suggestions, and provide effective schemes for the improvement of ecological environment.

1) Industrial water utilization stage

In order to make each region have sufficient water resources, China has implemented various plans and strategies, such as "the South-to-North Water Transfer Project" and "the Three Gorges Dam Project", to maintain the balance of water resources. In "the Guidance Catalogue for Industrial Structure Adjustment", it proposes efficient water transmission and distribution, water-saving irrigation technology, encouraging comprehensive utilization of environmental protection and resource conservation, implementing national water-saving actions, strengthening water-saving and efficiency in agriculture, reducing industrial water emissions, and encouraging water recycling. For traditional industries with high water consumption and low efficiency, it is necessary to accelerate the transformation of management forms, optimize the industrial structure, eliminate backward production capacity according to law, reduce the production of industrial wastewater from the source, and introduce new water-saving and emission reduction technologies in areas with conditions. It is necessary to strengthen industrial water recycling and take the road of sustainable development.

2) Pollutant treatment stage

Rapid economic growth is the main reason for the increase of pollutants. Provinces with strong industrial industries, such as Jiangsu, Guangdong and Hebei, have high industrial added value, but the ecological pollution problem is also very serious. While maintaining economic development, these provinces should make full use of their own economic and talent advantages, improve the cleaner production level of enterprises, improve the technical improvement of industrial wastewater treatment facilities, ensure the synchronous development of pollution control and economy, and take the new road of industrialization. Xinjiang has redundant input but insufficient output, slow GDP growth and high COD emission. It is necessary to increase the investment in industrial wastewater treatment facilities to ensure that COD emission meets the standard.

3) Policy suggestion

In order to build a society in which human beings and ecology coexist harmoniously, relevant departments should improve the legal system, actively formulate policies conducive to ecological environment protection and pollutant emission, strengthen inter regional cooperation and learn from areas with good ecological environment. Enterprises should adhere to optimizing industrial structure and promoting technological progress. All regions can take the pollutant emission compliance rate as the work assessment of local governments and enterprises. All provinces should vigorously introduce scientific and technological innovative talents, improve the compliance rate of industrial wastewater treatment, actively publicize water conservation, improve the awareness of water conservation and emission reduction of enterprises. Improve the level of public participation, and promote the coordination between economic and social development and ecological environment. 


\section{References}

[1] Wang M, Chen Y, Zhou Z. A novel stochastic two-stage DEA model for evaluating industrial production and waste gas treatment systems. Sustainability, 2020, 12(6): 1-17.

[2] Soltanjalili M J, Haddad O B, Marino M A. Operating water distribution networks during water shortage conditions using hedging and intermittent water supply concepts. Journal of Water Resources Planning \& Management, 2013, 139(6): 644-659.

[3] Medrano H, Tomás M, Martorell S, et al. Improving water use efficiency of vineyards in semi-arid regions. A review. Agronomy for Sustainable Development, 2015, 35(2): 499-517.

[4] Chen X H, Wu C Y, Kuang H B. Research on the evaluation of enterprises' green growth efficiency based on DEMATEL-DEA. Journal of Systems Science and Information, 2015, 3(5): 451-462.

[5] Song M L, An Q X, Zhang W, et al. Environmental efficiency evaluation based on data envelopment analysis: A review. Renewable \& Sustainable Energy Reviews, 2012, 16(7): 4465-4469.

[6] Chen C H, Liu H H, Tang L J, et al. A range adjusted measure of super-efficiency in integer-valued data envelopment analysis with undesirable outputs. Journal of Systems Science and Information, 2021, 9(4): 378-398.

[7] Lin B, Song D, Liu Z Y. A model of aircraft support concept evaluation based on DEA and PCA. Journal of Systems Science and Information, 2018, 6(6): 563-576.

[8] Fan J P, Yue W Z, Wu M Q. Dealing with interval DEA based on error propagation and entropy: A case study of energy efficiency of regions in China considering environmental factors. Journal of Systems Science and Information, 2015, 3(6): 538-548.

[9] Wang Y S, Xu H, Bian Y W. Industrial water use system efficiency evaluation: A two-stage DEA model considering pollutants disposability. Chinese Journal of Management Science, 2016, 24(3): 169-176.

[10] Tian C H, Zhao T, Zhong X U, et al. Analysis of technical efficiency of agricultural efficient water-saving technology based on DEA method in Xinjiang. Water Saving Irrigation, 2017(1): 90-93.

[11] Pan W B, Huang L, Zhao L L. An integrated DEA model allowing decomposition of eco-efficiency: A case study of China. Journal of Systems Science and Information, 2017, 5(5): 473-488.

[12] Deng G Y, Li L, Song Y N. Provincial water use efficiency measurement and factor analysis in China: Based on SBM-DEA model. Ecological Indicators, 2016, 69: 12-18.

[13] Chang Y J, Zhu D. Water utilization and treatment efficiency of China's provinces and decoupling analysis based on policy implementation. Resources Conservation and Recycling, 2020, 168: 105270.

[14] Zhu D, Tang L, Xie Q W, et al. Efficiency assessment of water resource utilization in the Chinese provincial capital cities based on data envelopment analysis. Acta Ecologica Sinica, 2020, 40(6): 1956-1966.

[15] Li Y J, Shi X, Emrouznejad A, et al. Environmental performance evaluation of Chinese industrial systems: A network SBM approach. Journal of the Operational Research Society, 2018, 69(6): 825-839.

[16] Hu P, Chen N, Li Y J, et al. Efficiency evaluation of water consumption in a Chinese province-level region based on data envelopment analysis. Water, 2018, 10(6): 1-21.

[17] Wang M Q, Huang Y, Li D. Assessing the performance of industrial water resource utilization systems in China based on a two-stage DEA approach with game cross efficiency. Journal of Cleaner Production, 2021, 312: 127722 .

[18] Song M L, Wang S H, Liu W. A two-stage DEA approach for environmental efficiency measurement. Environmental Monitoring and Assessment, 2014, 186(5): 3041-3051.

[19] Chen S Z, Wu D S. Adapting ecological risk valuation for natural resource damage assessment in water pollution. Environmental Research, 2018, 164: 85-92.

[20] Zhang X T, Yu J J. Water use efficiency assessment of Chinese provinces based on a data envelopment analysis model with undesirable outputs. Journal of Water Resources Research, 2017, 6(2): 138-147.

[21] Hailu A, Terrence S, Veeman. Non-parametric productivity analysis with undesirable outputs: An application to the Canadian pulp and paper industry. American Journal of Agricultural Economics, 2001, 83(3): 605-616.

[22] Seiford L M, Zhu J. Modeling undesirable factors in efficiency evaluation. European Journal of Operational Research, 2002, 142(1): 16-20. 
[23] Ali A I, Seiford L M. Translation invariance in data envelopment analysis. Operations Research Letters, 1990, 9(6): 403-405.

[24] Pastor J T. Chapter 3 Translation invariance in data envelopment analysis: A generalization. Annals of Operations Research, 1996, 66(2): 91-102.

[25] Färe R, Grosskopf S. Modeling undesirable factors in efficiency evaluation: Comment. European Journal of Operational Research, 2004, 157(1): 242-245.

[26] Dai Q Z, Li Y J, Lei X Y, et al. A DEA-based incentive approach for allocating common revenues or fixed costs. European Journal of Operational Research, 2021, 292(2): 675-686.

[27] Dai Q Z, Li L, Lei X Y, et al. Considering monopoly maintenance cost for an automobile purchase in China: A DEA-based approach. Journal of Systems Science and Complexity, 2019, 32(4): 1167-1179.

[28] Dai Q Z, Li Y J, Liang L. Allocating fixed costs with considering the return to scale: A DEA approach. Journal of Systems Science and Complexity, 2016, 29(5): 1320-1341.

[29] Xi W, Cheng X R. The difference of capital input and productivity in service industries: Based on four stages bootstrap-DEA model. Journal of Systems Science and Information, 2018, 6(4): 320-335.

[30] Dai Q Z, Lei X Y, Li Y J. Allocating emissions based on DEA and maximizing the whole satisfaction degree. Systems Engineering — Theory \& Practice, 2014, 34(4): 917-924.

[31] Xie Q W, Hu P, Jiang A, et al. Carbon emissions allocation based on satisfaction perspective and data envelopment analysis. Energy Policy, 2019, 132: 254-264.

[32] Xie Q W, Li R, Zou Y P, et al. A two-stage method for improving discrimination and variable selection in DEA models. IMA Journal of Management Mathematics, 2021. https://doi.org/10.1093/imaman/dpab023.

[33] Chen L, Wang Y M, Wang L. Eco-efficiency measurement and decomposition in the two-stage DEA analysis framework. Systems Engineering — Theory \& Practice, 2016, 36(3): 642-649.

[34] Feng Z J, Chen W. R \& D innovation efficiency of Chinese high-tech industries — Based on two-stage network DEA model with constrained resources. Systems Engineering — Theory \& Practice, 2014, 34(5): $1202-1212$.

[35] Chen K H, Guan J C. Network DEA-based efficiency measurement and decomposition for a relational two-stage production system with shared inputs. Systems Engineering — Theory \& Practice, 2011, 31(7): $1211-1221$.

[36] Ma J F, He F. DEA efficiency evaluation of hybrid multi-stage system with intermediate measure exits. Systems Engineering - Theory \& Practice, 2015, 35(11): 2874-2884.

[37] Yuan H H, Hu Y P, Qi H L. Some problems in determining COD in water with potassium dichromate method. Water Purification Technology, 2005, 24(4): 67-68.

[38] Yang M, Li Y J, Liang L. A generalized equilibrium efficient frontier data envelopment analysis approach for evaluating DMUs with fixed-sum outputs. European Journal of Operational Research, 2015, 246(1): 209-217.

[39] Yang F, Wu D D, Liang L, et al. Competition strategy and efficiency evaluation for decision making units with fixed-sum outputs. European Journal of Operational Research, 2011, 212(3): 560-569.

[40] Liang L, Feng Y, Cook W D, et al. DEA models for supply chain efficiency evaluation. Annals of Operations Research, 2006, 145(1): 35-49.

[41] Kao C, Hwang S N. Efficiency decomposition in two-stage data envelopment analysis: An application to non-life insurance companies in Taiwan. European Journal of Operational Research, 2008, 185(1): 418-429.

[42] Si X L, Liang L, Jia G Z, et al. Proportional sharing and DEA in allocating the fixed cost. Applied Mathematics \& Computation, 2013, 219(12): 6580-6590.

[43] Liang L, Cook W D, Zhu J. DEA models for two-stage processes: Game approach and efficiency decomposition. Naval Research Logistics, 2008, 55(7): 1-11.

[44] Zhao L S, Sun C Z, Liu F C. Two-stage utilization efficiency of the interprovincial water resources under environmental constraint and its influence factors in China. China Population Resources and Environment, 2017, 27(5): 27-36.

[45] Xie Q W, Xu Q F, Zhu D, et al. Fair allocation of wastewater discharge permits based on satisfaction criteria using data envelopment analysis. Utilities Policy, 2020, 66: 101078. 
[46] Zhang J J, Wu Q, Zhou Z X. A two-stage DEA model for resource allocation in industrial pollution treatment and its application in China. Journal of Cleaner Production, 2019, 228: 29-39.

[47] Su Q M, Chen X. Efficiency analysis of metacoupling of water transfer based on the parallel data envelopment analysis model: A case of the South-North water transfer Project-Middle route in China. Journal of Cleaner Production, 2021, 313: 127952.

[48] Zhang C J, Hua R, Shi Z, et al. Study on water resources consumption and environmental pollution of China's provinces under different economic development levels. Natural Resources Forum, 2021, 45(3): 305-325.

[49] Wang Y. Chinese provincial water resources utility efficiency and its influencing factors based on superefficiency DEA and tobit model. China Rural Water and Hydropower, 2015(5): 41-44+52.

[50] Bian Y W, Yan S, Xu H. Efficiency evaluation for regional urban water use and wastewater decontamination systems in China: A DEA approach. Resources. Conservation and Recycling, 2014, 83: 15-23.

[51] Li Y, Liu J, Ang S, et al. Performance evaluation of two-stage network structures with fixed-sum outputs: An application to the 2018 winter Olympic Games. Omega, 2020, 102: 102342. 